\title{
Proteína Bruta para Suínos Machos Castrados Mantidos em Ambiente de Conforto Térmico dos 15 aos 30 kg$^{1}$
}

\author{
Melissa Izabel Hannas ${ }^{2}$, Rita Flávia Miranda de Oliveira ${ }^{3}$, Juarez Lopes Donzele ${ }^{3}$, Aloízio \\ Soares Ferreira ${ }^{3}$, Darci Clementino Lopes ${ }^{3}$, José Luiz Soares ${ }^{4}$, Andréa Monica Moretti ${ }^{5}$
}

\begin{abstract}
RESUMO - Este experimento foi realizado para determinar a exigência de proteína bruta para suínos mestiços (Landrace x Large White), machos, castrados dos 15 aos $30 \mathrm{~kg}$, mantidos em ambiente de conforto térmico. Durante o período experimental, a temperatura da sala manteve-se em $23,1 \pm 1,19^{\circ} \mathrm{C}$, com umidade relativa de $80,6 \pm 4,59 \%$ e índice de temperatura do globo e umidade de $69,85 \pm 1,38$. Foi usado um total de 60 leitões mestiços, machos castrados, com peso médio inicial de $14,8 \pm 0,85 \mathrm{~kg}$ e final de $29,3 \pm 2,42 \mathrm{~kg}$. Foi usado delineamento de blocos ao acaso, com cinco tratamentos $(17,0 ; 18,0 ; 19,0 ; 20,0 ;$ e 21,0\% de proteína bruta), seis repetições e dois animais por unidade experimental. O nível de proteína bruta na ração influenciou o ganho de peso diário e os consumos de proteína e lisina diários, que aumentaram linearmente. Entretanto, a conversão alimentar diminuiu linearmente. Não houve efeito do nível de proteína sobre os consumos de ração e energia diários. A taxa de deposição de gordura não foi influenciada, enquanto a taxa de deposição de proteína aumentou quadraticamente até o nível de 20,0\% de proteína bruta. Os pesos absolutos do fígado e do intestino e o peso relativo do fígado aumentaram linearmente com o crescente nível de proteína bruta da ração. A concentração de uréia plasmática não foi influenciada pelos níveis de proteína bruta da ração. Suínos mestiços, machos, castrados de 15 a $30 \mathrm{~kg}$, mantidos em ambiente de conforto térmico exigem $20,0 \%$ de proteína bruta na ração, correspondente a $0,90 \%$ de lisina total ou 57 g de proteína/Mcal ED. O nível de uréia no plasma sangüíneo não foi um parâmetro adequado para estimar a exigência de proteína bruta.
\end{abstract}

Palavras-chave: fase inicial, leitões, proteína bruta, termoneutralidade

\section{Crude Protein for Barrows in Thermal Comfort from 15 to $30 \mathrm{~kg}$}

\begin{abstract}
This experiment was carried out to evaluate the requirement of crude protein for initial growing crossbred barrows (Landrace x Large White), from 15 to $30 \mathrm{~kg}$, maintained in thermal comfort. During the experimental period, the room temperature was maintained at $23.1 \pm 1.19^{\circ} \mathrm{C}$, with relative humidity at $80.6 \pm 4.59 \%$ and Black Globe Index Humidity at $69.8 \pm 1.38$. Sixty crossbred barrows with initial average weight of $14.8 \pm 0.85 \mathrm{~kg}$ and final weight of $29.3 \pm 2.42 \mathrm{~kg}$, were used. A completely randomized blocks design, with five treatments $(17.0,18.0,19.0,20.0$ and $21.0 \%$ of crude protein), six replicates and two animal per experimental unit was used. The dietary crude protein level influenced the daily weight gain and protein and lysine daily intakes that linearly increased. However, the feed:gain ratio linearly decreased. There was no effect of crude protein level on diet and digestible energy daily intakes. The fat deposition rate was not affected, while the protein deposition rate in a quadratic way increased up to the crude protein level of $20.0 \%$. The absolute and relative weight of liver linearly increased as dietary crude protein level increased. The urea plasma concentration was not affected by the dietary crude protein level. Crossbred barrows pigs, from 15 to $30 \mathrm{~kg}$, maintained under thermal comfort, require $20.0 \%$ of dietary crude protein, corresponding to $0.901 \%$ of total lysine or $57 \mathrm{~g}$ of protein/Mcal DE. The plasma urea concentration did not constitute to be an adequate parameter to estimate the crude protein requirement.
\end{abstract}

Key Words: crude protein, initial phase, piglets, thermoneutrality

\section{Introdução}

A temperatura ambiente pode influenciar a produtividade dos suínos, por alterar a troca de calor com o ambiente, a taxa de ingestão de alimento e o ganho de peso e, concomitantemente, afetar ou mudar as exigências em nutrientes dos animais, entre outras respostas (EFFECT..., 1981; DAUNCEY e INGRAM, 1983; LE DIVIDICH e NOBLET, 1986; CAMPBELL e TAVERNER, 1988; e RINALDO e LE DIVIDICH, 1991). De acordo com PERDOMO (1994), a reação do suíno ao estresse por calor pode ser constatada do ponto de vista fisiológico e metabólico, pelas alterações na temperatura corporal, pelos

\footnotetext{
${ }^{1}$ Parte da Tese de Mestrado do primeiro autor - Projeto financiado pela FAPEMIG.

2 Estudante de Doutorado - UNESP, Jaboticabal, SP. E.mail: mhannas@fcav.unesp.br

3 Professor do DZO-UFV. E.mail: flavia@mail.ufv.br; donzele@mail.ufv.br; alsofe@mail.ufv.br; dclopes@mail.ufv.br

${ }^{4}$ Agroceres - Ponta Grossa, PR. E.mail: zeze@agroceres.com.br

${ }^{5}$ Estudante do curso de Zootecnia - UFV.
} 
movimentos respiratórios e cardíacos, bem como pela mobilização de gordura corporal dos animais, e do ponto de vista da produtividade, por redução no consumo voluntário de ração e perda de peso.

As exigências nutricionais dos suínos têm sido estabelecidas em ambientes termicamente controlados, provavelmente para evitar que os animais sejam expostos a temperaturas extremas (altas ou baixas). No entanto, pode-se considerar que isto seja válido para as pesquisas realizadas nos Estados Unidos e na Europa, porque no Brasil a determinação das exigências nutricionais para suínos tem sido feita sem considerar as condições ambientais que podem influenciar os resultados obtidos.

Como exemplo de que as exigências nutricionais podem ser influenciadas pela temperatura ambiente, vários trabalhos têm sido realizados. FERGUSSON e GOUS (1997), estudando o efeito do nível de proteína bruta na ração e da temperatura ambiental $(18,22,26$ e $30^{\circ} \mathrm{C}$ ) sobre o desempenho e a composição corporal de suínos na fase inicial de crescimento (13 a $27 \mathrm{~kg}$ ), verificaram que o ganho de peso decresceu com a diminuição do nível de proteína bruta na ração, enquanto a temperatura de $26^{\circ} \mathrm{C}$ promoveu os melhores ganho de peso $(680 \mathrm{~g} / \mathrm{dia})$ e conversão alimentar $(1,868)$. Constatou-se ainda que o nível de proteína bruta na ração influenciou a composição de proteína e gordura corporal dos animais, enquanto a temperatura influenciou apenas o conteúdo de gordura corporal dos suínos.

Este estudo foi conduzido para avaliar as exigências nutricionais em proteína bruta para suínos machos castrados mantidos em ambiente de conforto térmico $\left(23^{\circ} \mathrm{C}\right)$, dos 15 aos $30 \mathrm{~kg}$.

\section{Material e Métodos}

O experimento foi conduzido no Setor de Suinocultura do Departamento de Zootecnia da Universidade Federal de Viçosa.

Foram utilizados 60 leitões mestiços (Landrace $\mathrm{x}$ Large White), machos castrados, em fase inicial de crescimento, com peso inicial médio de $14,8 \pm 0,85$ $\mathrm{kg}$ e idade média de $54 \pm 2,5$ dias. Foi usado delineamento experimental de blocos casualizados, com cinco tratamentos $(17,18,19,20$ e $21 \%$ de proteína bruta na ração), seis repetições e dois animais por unidade experimental, mantidos em ambiente de conforto térmico. Na formação dos blocos, foram considerados o peso inicial e o grau de parentesco dos animais.
Os animais, em grupos de dois, foram alojados em gaiolas metálicas, suspensas, com piso ripado e laterais teladas, providas de comedouro semi-automático e bebedouro (tipo chupeta), mantidas em sala de alvenaria com piso de creche, janelas de vidro tipo basculante e forro de madeira.

A temperatura interna da sala foi mantida por meio de um conjunto de seis aquecedores elétricos, distribuídos em dois corredores, a aproximadamente $40 \mathrm{~cm}$ do piso, e por um conjunto de dois aparelhos de ar condicionado de 18.000 BTU cada, sendo ambos os conjuntos ligados a termostatos.

As condições ambientais no interior das salas foram monitoradas diariamente, durante todo o período experimental, três vezes ao dia, por meio de termômetros de bulbo seco e bulbo úmido, de máxima e mínima e termômetro de globo negro, mantidos em uma gaiola vazia no centro da sala, à meia altura do corpo do animal.

As leituras dos termômetros foram posteriormente, convertidas, segundo BUFFINGTON et al. (1977) em um único valor (Índice de Temperatura de Globo e Umidade - ITGU), caracterizando o ambiente térmico a que os animais foram submetidos, a partir da seguinte equação:

em que

$$
\text { ITGU }=\text { Tgn }+0,36 \text { Tpo }-330,08
$$

Tgn = temperatura de globo negro, em K; e

Tpo = temperatura de ponto de orvalho, em $\mathrm{K}$.

As rações experimentais, isoenergéticas, (Tabela 1) foram devidamente suplementadas com minerais e vitaminas, conforme recomendações de ROSTAGNO et al. (1992). Os níveis de proteína bruta na ração foram obtidos por meio de variação proporcional nas quantidades de milho, farelo de soja e glúten de milho, corrigindo-se, também, o nível de energia pela variação nas quantidades de amido. As rações experimentais e a água foram fornecidas à vontade aos animais.

As sobras de ração e os animais foram pesados semanalmente, até o final do experimento, quando os animais atingiram o peso de $29,3 \pm 2,42 \mathrm{~kg}$, para averiguação do consumo de ração, do ganho de peso e da conversão alimentar.

Ao término do período experimental, os animais foram colocados em jejum alimentar por 24 horas. Após o jejum, um animal de cada unidade experimental, com peso mais próximo de $30 \mathrm{~kg}$, foi abatido por desensibilização e sangramento. Após o abate, os animais foram depilados e eviscerados, sendo que os órgãos (fígado, pulmões, rins, coração, intestino delgado sem mesentério e estômago) foram retirados, 
Tabela 1 - Composição centesimal das rações experimentais Table 1 - Centesimal composition of experimental diets

\begin{tabular}{|c|c|c|c|c|c|}
\hline \multirow[t]{2}{*}{$\begin{array}{l}\text { Ingrediente }(\%) \\
\text { Ingredient }\end{array}$} & \multicolumn{5}{|c|}{$\begin{array}{c}\text { Níveis de proteína bruta }(\%) \\
\text { Crude protein levels }\end{array}$} \\
\hline & 17 & 18 & 19 & 20 & 21 \\
\hline Milho $(8,2 \% \text { PB })^{1}$ (Corn) & 49,79 & 52,71 & 55,64 & 58,57 & 61,50 \\
\hline Farelo soja $(46,15 \% \mathrm{~PB})^{1}$ (Soybean meal) & 20,81 & 22,03 & 23,25 & 24,48 & 25,70 \\
\hline Glúten milho $(62,64 \% \mathrm{~PB})^{1}$ (Corn gluten) & 5,29 & 5,61 & 5,92 & 6,23 & 6,54 \\
\hline Fosfato bicálcico (Dicalcium phosphate) & 1,66 & 1,63 & 1,60 & 1,57 & 1,54 \\
\hline Calcário(Limestone) & 1,09 & 1,09 & 1,09 & 1,09 & 1,09 \\
\hline Mistura mineral $^{2}$ (Mineral mix) & 0,10 & 0,10 & 0,10 & 0,10 & 0,10 \\
\hline Mistura vitamínica ${ }^{3}$ (Vitamin mix) & 0,10 & 0,10 & 0,10 & 0,10 & 0,10 \\
\hline Sal comum (Salt) & 0,34 & 0,34 & 0,34 & 0,34 & 0,34 \\
\hline BHT & 0,01 & 0,01 & 0,01 & 0,01 & 0,01 \\
\hline Óleo de soja (Soybean oil) & 1,83 & 1,83 & 1,83 & 1,83 & 1,83 \\
\hline Amido (Corn starch) & 18,15 & 13,90 & 9,65 & 5,40 & 1,15 \\
\hline Areia lavada (Washed sand) & 0,83 & 0,65 & 0,47 & 0,28 & 0,10 \\
\hline \multicolumn{6}{|l|}{ Composição calculada ${ }^{4}$} \\
\hline \multicolumn{6}{|l|}{ Calculated composition } \\
\hline Proteína bruta (Crude protein), $\%$ & 17,00 & 18,00 & 19,00 & 20,00 & 21,00 \\
\hline $\mathrm{ED}(D E), \mathrm{kcal} / \mathrm{kg}$ & 3500 & 3500 & 3500 & 3500 & 3500 \\
\hline Lisina (Lysine), \% & 0,766 & 0,811 & 0,856 & 0,901 & 0,946 \\
\hline Lisina digestível (Digestible lysine), $\%^{5}$ & 0,672 & 0,711 & 0,751 & 0,790 & 0,830 \\
\hline Metionina + cistina digestível ${ }^{5}(\%)$ & 0,513 & 0,543 & 0,573 & 0,603 & 0,633 \\
\hline \multicolumn{6}{|l|}{ Digestible methionine + cystine } \\
\hline Treonina digestível ${ }^{5}$ (Digestible threonine), $\%$ & 0,539 & 0,571 & 0,603 & 0,634 & 0,666 \\
\hline Triptofano digestível $(\%)^{5}$ & 0,184 & 0,195 & 0,206 & 0,217 & 0,228 \\
\hline \multicolumn{6}{|l|}{ Digestible thryptophan } \\
\hline $\mathrm{Ca}(\%)$ & 0,880 & 0,877 & 0,875 & 0,873 & 0,870 \\
\hline $\mathrm{P}(\%)$ & 0,398 & 0,398 & 0,397 & 0,397 & 0,397 \\
\hline \multicolumn{6}{|c|}{ 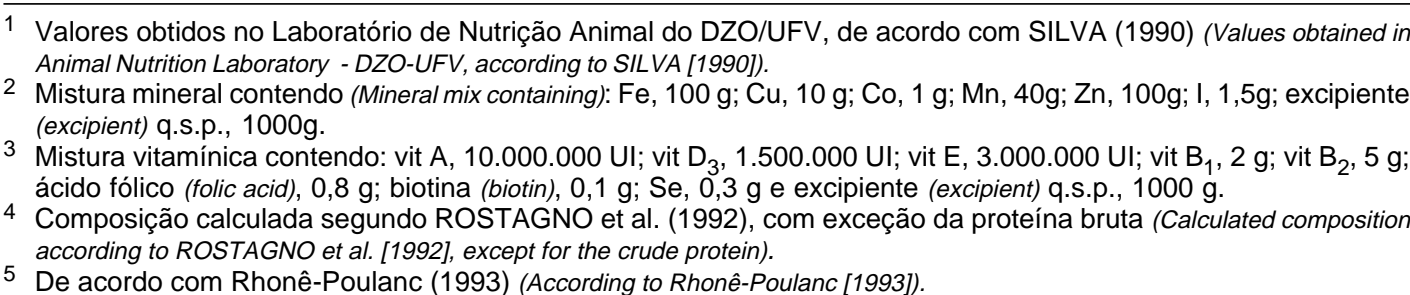 } \\
\hline
\end{tabular}

secados à sombra e, posteriormente, pesados.

Um grupo adicional de cinco leitões com peso médio de 15,0 $\pm 0,32 \mathrm{~kg}$ também foi abatido, seguindose o mesmo procedimento de abate dos animais no final do experimento, para determinação da composição da carcaça dos animais no início do experimento e posterior determinação das taxas de deposição de proteína e gordura, conforme técnica descrita por DONZELE et al. (1992a).

As carcaças inteiras (de todos os animais abatidos), evisceradas e sem sangue, incluindo cabeça e pés, foram pesadas e trituradas em "cutter" comercial de $30 \mathrm{HP}$ e $1775 \mathrm{rpm}$ por 15 minutos. Após homogeneização, retiraram-se amostras, que foram armazenadas em congelador a $-12^{\circ} \mathrm{C}$. Ao se prepararem as amostras para análises laboratoriais, em razão da alta concentração de gordura do material, proce- deu-se à pré-secagem em estufa, com ventilação forçada, a $\pm 60^{\circ} \mathrm{C}$, por 72 horas. Em seguida, realizouse pré-desengorduramento, pelo método a quente no extrator tipo "Soxlet", por quatro horas para posteriormente efetuar a moagem do material.

As amostras pré-secadas, pré-desengorduradas e moídas foram acondicionadas em vidros com tampa de polietileno devidamente identificadas para posteriores análises laboratoriais.

Os teores de água e gordura das amostras foram considerados para efeito da correção dos valores das análises posteriores. As análises de matéria seca, proteína e gordura das amostras foram feitas de acordo com SILVA (1990).

Os animais que não foram abatidos voltaram a receber as respectivas rações experimentais por um período de sete horas, das 12 às 19 h do mesmo dia, 
HANNAS et al.

Tabela 2 - Desempenho e taxas de deposição de proteína e gordura de leitões de 15 a $30 \mathrm{~kg}$ de peso alimentados com rações contendo níveis crescentes de proteína bruta e mantidos em conforto térmico

Table 2 - Performance and fat and protein deposition rates of piglets from 15 to $30 \mathrm{~kg}$ fed diets with crescent levels of crude protein and maintained in thermal comfort

\begin{tabular}{|c|c|c|c|c|c|c|}
\hline \multirow[t]{2}{*}{$\begin{array}{l}\text { Variáveis } \\
\text { Variables }\end{array}$} & \multicolumn{5}{|c|}{$\begin{array}{c}\text { Nível de proteína bruta }(\%) \\
\text { Crude protein levels }\end{array}$} & \multirow[b]{2}{*}{$\mathrm{CV}(\%)$} \\
\hline & 17 & 18 & 19 & 20 & 21 & \\
\hline $\begin{array}{l}\text { Ganho de peso diário }(\mathrm{g} / \mathrm{dia})^{1} \\
\text { Daily weight gain }(\mathrm{g} / \text { day })^{1}\end{array}$ & 517 & 579 & 595 & 669 & 635 & 9,44 \\
\hline $\begin{array}{l}\text { Consumo de ração (g/dia) } \\
\text { Feed intake (g/day) }\end{array}$ & 1212 & 1240 & 1279 & 1278 & 1263 & 8,00 \\
\hline $\begin{array}{l}\text { Consumo de proteína }(\mathrm{g} / \text { dia })^{1} \\
\text { Protein intake }(g / \text { day })^{1}\end{array}$ & 206 & 223 & 243 & 255 & 265 & 8,05 \\
\hline $\begin{array}{l}\text { Consumo de lisina }(\mathrm{g} / \mathrm{dia})^{1} \\
\text { Lysine intake }(\mathrm{g} / \text { day })^{1}\end{array}$ & 9,28 & 10,06 & 11,09 & 11,51 & 11,95 & 6,72 \\
\hline $\begin{array}{l}\text { Consumo energia digestível (kcal/dia) } \\
\text { Digestible energy intake (kcal/day) }\end{array}$ & 4241 & 4340 & 4478 & 4473 & 4420 & 8,00 \\
\hline $\begin{array}{l}\text { Conversão alimentar } \\
\text { Feed:gain } \text { ratio }^{1}\end{array}$ & 2,35 & 2,15 & 2,15 & 1,91 & 1,99 & 7,64 \\
\hline $\begin{array}{l}\mathrm{ED} / \mathrm{GPD}^{\mathrm{a}}(\mathrm{kcal} \mathrm{ED} / \mathrm{g} \mathrm{GP}) \\
D E / D W G^{a}(k c a l \mathrm{DE} / \mathrm{g} W G)\end{array}$ & 8,20 & 7,49 & 7,52 & 6,69 & 6,96 & \\
\hline $\begin{array}{l}\text { ED total retida na carcaça }(\mathrm{kcal} / \mathrm{dia})^{\mathrm{b}} \\
\text { Total DE retained in carcass }(k c a l / d a y)^{b}\end{array}$ & 1275 & 1469 & 1398 & 1324 & 1359 & \\
\hline $\begin{array}{l}\% \text { ED retida como proteína na carcaça/dia }{ }^{\mathrm{c}} \\
\% \text { DE retained as protein in carcass } / \text { day }\end{array}$ & 25,96 & 26,89 & 29,97 & 33,84 & 31,86 & \\
\hline $\begin{array}{l}\text { Relação energia:proteína } \\
\text { Energy:protein ratio }\end{array}$ & 20,59 & 19,46 & 18,43 & 17,54 & 16,68 & \\
\hline $\begin{array}{l}\text { Taxas de deposição na carcaça }(\mathrm{g} / \text { dia }) \\
\text { Deposition rates in the carcass }(\mathrm{g} / \text { day) } \\
\text { Proteína }^{2} \text { (Protein) } \\
\text { Gordura }(\text { Fat })\end{array}$ & $\begin{array}{c}58 \\
100\end{array}$ & $\begin{array}{c}70 \\
113\end{array}$ & $\begin{array}{c}74 \\
103\end{array}$ & $\begin{array}{l}79 \\
93\end{array}$ & $\begin{array}{l}76 \\
98\end{array}$ & $\begin{array}{l}9,00 \\
13,1\end{array}$ \\
\hline $\begin{array}{l}1 \text { Efeito linear (Linear effect) }(\mathrm{P}<0,01) \text {. } \\
2 \text { Efeito quadrático (Quadratic effect) }(\mathrm{P}<0,01) \text {. } \\
\text { a Eficiência de utilização de energia para ganho. } \\
\text { Efficiency of utilization of the } D E \text { for daily gain. } \\
\text { b Energia digestível total retida na carcaça. Calculac } \\
\text { FONTES (1999), como a taxa de deposição de pr } \\
\text { deposição de gordura ( } \mathrm{g} / \text { dia) multiplicada por } 9,46 \\
\text { proteína e } 1 \mathrm{~g} \text { de gordura, respectivamente (Total } \\
\text { factors according to FONTES (1999). (Calculated as prot } \\
\text { rate (g/day) multiplied by } 9.46 \text {, that correspond to the ene } \\
\text { c \% da energia digestível retida como proteína na c } \\
\text { in carcass by day). }\end{array}$ & $\begin{array}{l}\text { ando- } \\
\text { (g/dia } \\
\text { corres } \\
\text { energ } \\
\text { osition } \\
\text { ent to d } \\
\text { por di }\end{array}$ & $\begin{array}{l}\text { se os } \mathrm{f} \\
\text { ) multi } \\
\text { Donde } \\
\text { y retain } \\
\text { rate }(\mathrm{g} / \mathrm{c} \\
\text { eposit } 1 \\
\text { a (\% of }\end{array}$ & $\begin{array}{l}\text { de de } \\
\text { da p } \\
\text { ergia } \\
\text { carca } \\
\text { nultip } \\
\text { prote }\end{array}$ & $\begin{array}{l}\text { vers } \\
66, s \\
\text { ta pe } \\
\text { btain } \\
\text { by } 5.6 \\
d 1 \mathrm{~g}\end{array}$ & $\begin{array}{l}\text { acor } \\
\text { ada à t } \\
\text { eposit } \\
\text { sing cor } \\
\text { e fat de } \\
\text { t, respe }\end{array}$ & $\begin{array}{l}\text { rdo com } \\
\text { taxa de } \\
\text { itar } 1 \text { de } \\
\text { onversion } \\
\text { yeposition } \\
\text { pectively). } \\
\text { as protein }\end{array}$ \\
\hline
\end{tabular}

após o qual foram submetidos novamente a jejum de 12 horas, das $19 \mathrm{~h}$ às $7 \mathrm{~h}$ da manhã do dia seguinte, quando voltaram a receber as rações experimentais por um período de uma hora. A partir daí, foram submetidos a um segundo período de jejum de cinco horas. Após este procedimento, foi coletado sangue por meio de punção no sinus orbital, em tubos de ensaio heparinizados acondicionados em balde com gelo. $\mathrm{O}$ sangue coletado foi imediatamente centrifugado durante 15 minutos, para retirada do plasma, que foi colocado em "freezer" para posterior análise de uréia. A uréia no plasma sangüíneo foi determinada por meio de "kit" enzimático Labtest usando a técnica de colorimetria.

As análises estatísticas das variáveis de desem- penho (ganho de peso, consumos de ração, energia, proteína e lisina e conversão alimentar), das taxas de deposição de proteína e gordura nas carcaças, dos peso dos órgãos e das concentrações plasmáticas de uréia foram realizadas por intermédio do programa computacional SAEG (Sistema de Análises Estatísticas e Genéticas), desenvolvido pela UNIVERSIDADE FEDERAL DE VIÇOSA - UFV (1982).

A estimativa da exigência de proteína bruta foi feita com base nos resultados de desempenho, consumos de proteína, lisina e energia, taxas de deposição de proteína e gordura na carcaça e energia digestível consumida utilizada para ganho de peso e energia digestível retida como proteína na carcaça. 


\section{Resultados e Discussão}

A temperatura interna da sala manteve-se durante todo o período experimental em $23,1 \pm 1,19^{\circ} \mathrm{C}$, com umidade relativa de $80,6 \pm 4,59 \%$, temperatura do globo negro de $22,7 \pm 1,02^{\circ} \mathrm{C}$ e índice de temperatura do globo e umidade (ITGU) de 69,8 $\pm 1,38$.

Os resultados de desempenho, consumos de energia, proteína e lisina diários, taxas de deposição de proteína e gordura na carcaça, eficiência de utilização de energia digestível para ganho, energia digestível total retida na carcaça e porcentagem de energia digestível retida como proteína na carcaça dos leitões de 15 aos $30 \mathrm{~kg}$ de peso, mantidos em ambiente de conforto térmico, estão apresentados na Tabela 2.

O ganho de peso diário (GPD) aumentou de forma linear $(\mathrm{P}<0,01)$, em razão do aumento dos níveis de proteína bruta $(\mathrm{PB})$ na ração, conforme a equação $\hat{\mathrm{Y}}=0,08688+0,02703 \mathrm{~PB}\left(\mathrm{r}^{2}=0,72\right)$. Embora tenha ocorrido efeito linear, constatou-se que o nível de 20\% PB proporcionou o maior GPD, que foi $5,3 \%$ superior àquele verificado no nível de $21 \%$ PB. De forma semelhante, OLIVEIRA et al. (1997a) observaram GPD de $655 \mathrm{~g} /$ dia para leitões de 15 a 30 $\mathrm{kg}$ mantidos em ambiente de conforto térmico, recebendo rações contendo $3500 \mathrm{kcal}$ de ED e 19,5\% PB. Estes resultados corroboram os de KYRIAZAKIS et al. (1991), SCHENK et al. (1992) e FERGUSON e GOUS (1997), que, trabalhando com suínos na fase inicial de crescimento, mantidos em ambiente de conforto, verificaram aumento linear do ganho de peso de suínos recebendo rações com níveis crescentes de PB. Estes resultados diferem, porém, daqueles obtidos por COELHO et al. (1987a), que não observaram diferença no ganho de peso diário dos suínos de 15 a $30 \mathrm{~kg}$ recebendo rações com níveis de PB que variaram de 14 a $22 \%$, mantidos em ambiente com temperaturas máximas e mínimas médias de 25,4 e $19,1^{\circ} \mathrm{C}$, respectivamente.

O consumo de ração diário (CRD) não foi influenciado pelos níveis de $\mathrm{PB}$ na ração, estando de acordo com os resultados de COELHO et al. (1987a), FRIESEN et al. (1994) e MORETO et al. (1998), que não observaram efeito dos níveis de proteína e lisina da ração sobre o consumo de suínos nas fases de 15 a 30 e 34 a $72 \mathrm{~kg}$, respectivamente. Estes resultados são indicativos de que suínos na fase inicial de crescimento (15 a $30 \mathrm{~kg}$ ) parecem não ajustar o consumo, em razão da concentração de proteína bruta ou lisina da ração. No entanto, FERGUSON e GOUS (1997) verificaram que suínos dos 13 aos $30 \mathrm{~kg}$ de peso mantidos em ambiente de conforto aumentaram o consumo de ração de forma quadrática até o nível de $15,1 \%$ PB, quando receberam rações contendo níveis de $\mathrm{PB}$ que variaram de 23 a 9,3\%, embora tenham mantido a mesma qualidade de proteína nas rações.

Não se observou efeito dos níveis de proteína bruta da ração sobre o consumo de energia diário. $\mathrm{O}$ fato de as rações serem isoenergéticas e o consumo de ração não ter variado entre os tratamentos justifica este resultado.

Os consumos de proteína (CPD) e lisina diários aumentaram de forma linear $(\mathrm{P}<0,01)$ com o aumento dos níveis de $\mathrm{PB}$ da ração, conforme as equações $\hat{\mathrm{Y}}=16,6748+11,8411 \mathrm{~PB}\left(\mathrm{r}^{2}=0,96\right)$ e $\hat{\mathrm{Y}}=-1,68298$ $+0,656729 \mathrm{~PB}\left(\mathrm{r}^{2}=0,92\right)$, respectivamente. Como não ocorreu variação significativa no $\mathrm{CRD}$, os aumentos lineares nos consumos de proteína bruta e lisina estão diretamente relacionados aos seus níveis nas rações. Os resultados obtidos corroboram os encontrados por FRIESEN et al. (1994) e SOUZA (1997), que também verificaram aumento nos consumos de proteína bruta e lisina dos suínos na fase inicial de crescimento recebendo rações com níveis crescentes de proteína e lisina, respectivamente.

O aumento do consumo de proteína diário e, conseqüentemente, de lisina pode justificar a melhora do ganho de peso dos animais. Diferentes autores (COELHO et al., 1987b; LIMA et al., 1990; SCHENCK et al. 1992; e FERGUSON e GOUS, 1997) também observaram efeito positivo do nível de lisina sobre o GPD de suínos, estando de acordo com o relato de KYRIAZAKIS (1994) de que, em condições de termoneutralidade, o crescimento de suínos pode ser limitado em razão do baixo consumo de proteína.

Por outro lado, SOUZA (1997), trabalhando com suínos machos castrados de 15 a $30 \mathrm{~kg}$ de peso, mantidos em ambiente cujas temperaturas máxima e mínima médias foram $26,8 \pm 2,07$ e $19,0 \pm 1,84^{\circ} \mathrm{C}$, respectivamente, não observaram efeito dos níveis crescentes de lisina sobre o ganho de peso diário.

As variações observadas entre os resultados dos diferentes trabalhos podem estar associadas a fatores como genótipo, ambiente, rações experimentais, status imunológico dos animais, entre outros.

Os níveis de $\mathrm{PB}$ da ração melhoraram $(\mathrm{P}<0,01)$ a conversão alimentar, que reduziu de forma linear, conforme a equação $\hat{\mathrm{Y}}=4,13844-0,105448 \mathrm{~PB}$ $\left(\mathrm{r}^{2}=0,74\right)$. Resultados semelhantes foram observados por SCHENCK et al. (1992) e KERR et al. (1995). Entretanto, SOUZA (1997) não observou melhora na CA de suínos de 15 a 30 kg, em razão dos 
níveis crescentes de lisina da ração.

Apesar de ter ocorrido efeito linear, constatou-se que o nível de $20 \%$ de proteína bruta proporcionou os melhores resultados de conversão alimentar. A melhora gradativa na eficiência da utilização da energia digestível para ganho, que variou de 8,20 a 6,69 kcal de ED/g de ganho de peso, associada ao aumento também gradativo na proporção de energia retida como proteína na carcaça de 25,96 a 33,84\%, entre os níveis de 17 e $20 \%$ PB, justificam a melhora linear da conversão alimentar até o nível de $20 \%$ PB (Tabela 2).

A piora da conversão alimentar $(\mathrm{P}<0,05)$ observada no nível de $21 \%$ PB, em relação ao de $20 \%$, devese, possivelmente, ao aumento de $4 \%$ na quantidade de energia requerida por grama de ganho de peso e à redução de $6,2 \%$ na proporção da energia, que foi retida como proteína na carcaça naquele nível.

Considerando os resultados de energia digestível total retida na carcaça por dia, constatou-se que a melhor CA não ocorreu nos níveis de $\mathrm{PB}$, nos quais se observaram as maiores eficiências de retenção de energia, $18 \%(33,85 \%)$ e $19 \%(31,22 \%) \mathrm{PB}$, mas sim nos níveis em que a porcentagem de energia retida como proteína foi maior. Com base nesta constatação, pode-se inferir que a variação na eficiência com que os suínos utilizam diferentes rações estaria diretamente relacionada à proporção com que a energia é depositada como proteína e gordura na carcaça. $\mathrm{O}$ fato de a deposição de proteína agregar maior quantidade de água $(1: 5,26)$ em relação à de gordura (KYRIAZAKIS et al., 1994) explica o fato de a melhor conversão alimentar ter ocorrido no nível de $20 \%$ PB.

A taxa de deposição de gordura na carcaça (TDG) não foi influenciada pelos tratamentos, enquanto a taxa de deposição de proteína (TDP) variou $(\mathrm{P}<0,01)$ de forma quadrática até o nível de 20,22\% $\mathrm{PB}$ da ração, segundo a equação $\hat{\mathrm{Y}}=-684,993+$ $75,456 \mathrm{~PB}-1,86539 \mathrm{~PB}^{2}\left(\mathrm{r}^{2}=0,98\right)$. Estes resultados estão em acordo com os obtidos por KEER et al. (1995), os quais constataram que a redução em quatro unidades percentuais da $\mathrm{PB}$ da ração de suínos na fase de crescimento e terminação, de 19 e $16 \%$ para 15 e $12 \% \mathrm{~PB}$, respectivamente, resultaram em decréscimo da área muscular, enquanto a porcentagem de gordura corporal aumentou. Também concordam com os de OLIVEIRA et al. (1997b), os quais verificaram que, entre os níveis de 3350 e $3800 \mathrm{kcal}$ de ED, a taxa de deposição de proteína de leitões de 15 a $30 \mathrm{~kg}$, mantidos em ambiente de termoneutralidade, pareceu variar diretamente com o consumo de proteína.

Considerando que o nível de ED das rações estava acima da recomendação de FERREIRA et al. (1996), e que ocorreu aumento do consumo de proteína bruta entre os níveis de 20 e $21 \%$ PB na ração, pode-se presumir que o fato de a TDP não ter melhorado entre esses níveis indica que o potencial genético para deposição de proteína desses animais foi atingido no nível de $20 \%$ PB, em que a relação energia e proteína correspondeu a 17,54.

De acordo com relatos de BIKKER et al. (1994) e BIKKER e BOSCH (1996), não sendo a energia fator limitante, o ponto de inflexão na taxa de deposição de proteína define a exigência de proteína do animal. Com base nestes resultados, pode-se inferir que em suínos mantidos em ambiente de conforto térmico, alimentados à vontade com rações balanceadas, contendo proteína de boa qualidade nutricional e adequado nível de energia, o ganho de tecido magro pode ser limitado pelo potencial genético do animal.

A partir dos resultados de desempenho e taxas de deposição de proteína e gordura obtidos neste trabalho, constatou-se que os níveis de $\mathrm{PB}$ da ração influenciaram não somente o ganho dos suínos, como também a sua composição, alterando a proporção de gordura e carne.

Os resultados de pesos absoluto $(\mathrm{g})$ e relativo $(\%$ da carcaça) dos órgãos (fígado, rins, coração, estômago, intestino e pulmões) estão apresentados na Tabela 3. Apesar de ter ocorrido variação de 28,6\% no consumo de proteína diário entre os tratamentos, não se observou efeito do nível de PB da ração sobre os pesos, absoluto e relativo, de coração, estômago, pulmão e rins. No entanto, foi observado aumento linear $(\mathrm{P}<0,03)$ no peso absoluto do intestino delgado, sem mensentério, em razão do aumento dos níveis de $\mathrm{PB}$, conforme a equação $\hat{\mathrm{Y}}=403,617+34,2833 \mathrm{~PB}$ $\left(\mathrm{r}^{2}=0,52\right)$, enquanto o peso relativo deste órgão não foi influenciado, permitindo inferir que o acréscimo no peso de intestino delgado foi relacionado com o desenvolvimento animal.

Os níveis de PB da ração influenciaram de forma linear crescente os pesos absoluto $(\mathrm{P}<0,01)$ e relativo $(\mathrm{P}<0,05)$ do fígado, conforme as equações $\hat{\mathrm{Y}}=182,669+26,3900 \mathrm{~PB}\left(\mathrm{r}^{2}=0,86\right)$ e $\hat{\mathrm{Y}}=1,83987+$ $0,0809057 \mathrm{~PB}\left(\mathrm{r}^{2}=0,69\right)$, respectivamente.

Os resultados obtidos estão coerentes com os de CHEN et al. (1998), que observaram aumento do peso de fígado e da atividade da enzima arginase, em razão do aumento da concentração de proteína na ração de suínos na fase final de crescimento e terminação.

O aumento observado no consumo de proteína 
482 Rev. bras. zootec

diário pode justificar estes resultados, uma vez que o fígado é responsável, em grande parte, pelo metabolismo protéico, incluindo os processos de desaminação de aminoácidos, formação de uréia para remoção da amônia dos líquidos corporais, formação das proteína plasmáticas e interconversões entre diferentes aminoácidos e outros compostos importantes para o metabolismo do organismo (GUITON e HALL, 1997).

Os resultados da concentração de uréia plasmática podem ser observados na Tabela 4. Não foi observado efeito dos níveis de PB sobre a concentração de uréia plasmática, não constituindo parâmetro adequado para estimar a exigência de suínos nesta fase. Diferentes autores (DONZELE et al., 1992b; FONTES, 1999) também constataram que o nível de uréia no soro sangüíneo não foi parâmetro adequado para estimar a exigência de proteína e/ou lisina para leitões em fase inicial de crescimento. Entretanto, CHEN et al. (1995; 1998), LONGHMILLER et al. (1998) e MILLER et al. (1998) utilizaram a uréia plasmática para determinar a exigência de proteína de leitões em crescimento e em terminação, sob condições ambientais e genótipicas diferentes. $\mathrm{O}$ fato de ter sido usado plasma de somente um animal por unidade experimental, na determinação da concentração plasmática da uréia de cada tratamento, pode ter contribuído para que não ocorresse variação significativa entre os tratamentos. Segundo MILLER et al. (1998), é necessário coleta de sangue de seis machos por unidade experimental, para a formação de um "pool" sanguíneo, para que a determinação da concentração de uréia plasmática possa ser representativa como parâmetro na determinação da exigência de proteína.

Deve-se ressaltar que, no estudo em apreço, as rações contiveram diferentes quantidades do aminoácido lisina - o primeiro limitante nas rações para suínos -, que foram de 0,$766 ; 0,811 ; 0,856 ; 0,901$; e $0,946 \%$, respectivamente, para os níveis de $17,18,19$, 20 e $21 \%$ PB. Embora a relação entre o nível de PB e lisina tenha sido mantida constante em todos os tratamentos, a exigência de lisina associada ao nível de $20 \%$ PB correspondeu a $0,901 \%$ ou $11,54 \mathrm{~g}$ de lisina/dia. Estes valores foram equivalentes ou próximos aos citados por FERREIRA et al. (1996) e em NUTRIENTE... (1998), que recomendaram como exigência de lisina, para suínos na fase de 10 a $20 \mathrm{~kg}$ e 20 a $50 \mathrm{~kg}$, os valores de 1,15 e $0,95 \%$ de lisina total, respectivamente, para rações à base de milho e farelo de soja.

Tabela 3 - Pesos, absoluto (g) e relativo (\% da carcaça), de coração, estômago, fígado, pulmão, rins e intestino de suínos machos castrados de $30 \mathrm{~kg}$, alimentados com rações contendo níveis crescentes de proteína bruta e mantidos em ambiente de conforto térmico

Table 3 - Absolute $(\mathrm{g})$ and relative (\% of carcass) weights of heart, stomach, lung, kidney and gut of piglets with $30 \mathrm{~kg}$, fed diets with crescent crude protein levels and maintained in thermal confort

\begin{tabular}{|c|c|c|c|c|c|c|}
\hline \multirow{3}{*}{$\begin{array}{l}\text { Variáveis } \\
\text { Variable }\end{array}$} & \multirow{2}{*}{\multicolumn{6}{|c|}{$\begin{array}{c}\text { Níveis de proteína bruta }(\%) \\
\text { Crude protein levels }\end{array}$}} \\
\hline & & & & & & \\
\hline & 17 & 18 & 19 & 20 & 21 & $\mathrm{CV} \%$ \\
\hline & \multicolumn{6}{|c|}{ Peso absoluto (g) } \\
\hline & \multicolumn{6}{|c|}{ Absolute weight } \\
\hline Coração (Heart) & 130 & 126 & 131 & 127 & 128 & 6,63 \\
\hline Estômago (Stomach) & 225 & 198 & 233 & 211 & 217 & 8,95 \\
\hline Fígado $^{1}$ (Liver) & 649 & 627 & 704 & 710 & 736 & 6,56 \\
\hline Pulmão (Lung) & 296 & 299 & 307 & 300 & 304 & 9,52 \\
\hline Rins (Kidney) & 144 & 135 & 150 & 146 & 149 & 10,79 \\
\hline \multirow{3}{*}{ Intestino delgado ${ }^{2}$ (Small intestine) } & 1041 & 948 & 1071 & 1056 & 1159 & 10,5 \\
\hline & \multicolumn{6}{|c|}{ Peso relativo (\%) } \\
\hline & & & Relati & eight & & \\
\hline Coração (Heart) & 0,63 & 0,61 & 0,65 & 0,62 & 0,62 & 7,64 \\
\hline Estômago (Stomach) & 1,03 & 1,00 & 1,13 & 1,08 & 1,05 & 11,19 \\
\hline Fígado $^{3}$ (Liver) & 3,30 & 3,16 & 3,43 & 3,44 & 3,57 & 8,98 \\
\hline Pulmão (Lung) & 1,44 & 1,45 & 1,41 & 1,45 & 1,47 & 6,52 \\
\hline Rins (Kidney) & 0,70 & 0,68 & 0,69 & 0,71 & 0,69 & 9,42 \\
\hline Intestino delgado (Small intestine) & 5,31 & 4,79 & 5,17 & 5,07 & 5,37 & 8,30 \\
\hline
\end{tabular}


HANNAS et al.

Tabela 4 - Concentrações plasmáticas de uréia de leitões de $30 \mathrm{~kg}$ de peso, alimentadas com rações contendo níveis crescentes de proteína bruta e mantidos em condições de conforto

Table 4 - Plasma urea concentrations of barrows with $30 \mathrm{~kg}$ of weight fed diets with crescent crude protein levels and maintained in thermal comfort

\begin{tabular}{lcccccc}
\hline Item & \multicolumn{5}{c}{ Níveis de proteína bruta $(\%)$} \\
\cline { 2 - 6 } & 17 & 18 & 19 & 20 & 21 & CV\% \\
\hline Uréia $(\mathrm{mg} / \mathrm{dL})($ Urea $)$ & 34,54 & 39,65 & 41,19 & 34,82 & 38,96 & 20,48 \\
\hline
\end{tabular}

\section{Conclusões}

Suínos mestiços, das raças Landrace x Large White, machos castrados de 15 a $30 \mathrm{~kg}$, mantidos em ambiente de conforto térmico, exigem $20 \%$ de proteína bruta na ração, correspondente a $0,90 \%$ de lisina total ou $0,79 \%$ de lisina digestível, para melhor desempenho e deposição de proteína na carcaça.

O nível de uréia no plasma sangüíneo não constituiu parâmetro adequado para estimar a exigência de proteína bruta.

\section{Referências Bibliográficas}

BIKKER, P., BOSCH, M. Nutriente requeriments of pigs with high genetic potential for lean gain. In: SIMPÓSIO INTERNACIONAL SOBRE EXIGÊNCIAS NUTRICIONAIS DE AVES E SUÍNOS, 1996, Viçosa. Anais... Viçosa, 1996. p.223-239.

BIKKER, P., VERSTEGEN, M.W.A., BOSCH, M.W., 1994. Amino acid composition of growing pigs is affected by protein and energy intake. J. Nutr., 124:1961-1969.

BUFFINGTON, C.S., COLLAZO-AROCHO, A., CANTON, G.H. et al. 1977. Black globe humidity comfort index for dairy cows. St. Joseph: ASAE. 19p. (Paper 77-4517).

CAMPBELL, R.G., TAVERNER, M.R. 1988. Relationships between energy intake and protein and energy metabolism, growth and body composition of pigs kept at 14 or $32^{\circ} \mathrm{C}$ from 9 to $20 \mathrm{~kg}$. Lvstck. Prod. Sci., 18:289-303.

CHEN, H.Y., MILLER, P.S., LEWIS, A.J. et al. 1995. Changes in plasma urea concentration com be used to determine protein reuqerimments of two populations of pigs with different accretion rates. J. Anim. Sci., 73:2631-2639.

CHEN, H.Y., MILLER, P.S., LEWIS, A.J. 1998. The effect of protein intake on the growth performance, plasma urea concentration, liver weight, and arginase actuvity of finishing barrows and gilts. Nebr. Swi. Rep., p.34-35.

COELHO, L.S.S., COSTA, P.M.A., PEREIRA, J.A.A. et al. 1987a. Exigência de proteína de suínos de 15 a $30 \mathrm{~kg}$ de peso vivo. R. Soc. Bras. Zootec., 16:52-59.

COELHO, L.S.S., COSTA, P.M.A., SILVA, M.A. et al. $1987 \mathrm{~b}$. Exigência de lisina de suínos de 15 a $30 \mathrm{~kg}$ de peso vivo em rações de baixo nível protéico. R. Soc. Bras. Zootec., 16:60-71.

DAUNCEY, M.J., INGRAN, D.L. 1983. Evaluation of the effects of environmental temperature and nutrition on body composition. J. Agric. Sci., 101:351-358, 1983.
DONZELE, J.L., COSTA, P.M.A., ROSTAGNO, H.S. et al. 1992a. Efeitos de níveis de energia digestíveis na composição da carcaça de suínos de cinco a quinze quilos. R. Soc. Bras. Zootec., 21:1100-1106.

DONZELE, J.L., COSTA, P.M.A., ROSTAGNO, H.S. et al. $1992 b$. Níveis de proteína bruta para suínos de 5 a $15 \mathrm{~kg}$. $R$. Soc. Bras. Zootec., 21:1077-1083.

EFFECT OF ENVIRONMENTAL ON NUTRIENT REQUERIMENTS OF DOMESTIC ANIMALS. 1981. Washington, DC: NRC, NAS. 52p.

FERGUSSON, N.S., GOUS, M.R. 1997. The influence of heat production on voluntary food intake in growing pigs given protein-deficient diets. Br. Soc. Anim. Sci., 64:365-378.

FERREIRA, A.S., PUPA, J.M.R., SOUZA., A.M. Exigências nutricionais para suínos determinadas no Brasil. In: SIMPÓSIO INTERNACIONAL SOBRE EXIGÊNCIAS NUTRICIONAIS DE AVES E SUÍNOS, 1996, Viçosa. Anais... Viçosa: UFV, 1996, p.419-434.

FONTES, D.O. Níveis de lisina para leitoas com alto potencial genético para deposição de carne magra na carcaça, dos 15 aos 95 kg. Viçosa, MG: UFV, 1999. Tese (Doutorado em Zootecnia) - Universidade Federal de Viçosa, 1999.

FRIESEN, K.G., NELSSEN, J.L., GOODBAND, M.D. et al. 1994. Influence of dietary lysine on growth and carcass composition of higt-lean-growth gilts fed from 34 to 72 kilograms. J. Anim. Sci., 72:1761-1770.

GUITON, A.C., HALL, J.E. 1997. Tratado de fisiologia médica. Editora Guanabara Koogan, 9 ed. p.890.

KERR, B.J., MCKEITH, F.K., EASTER, R.A. 1995. Effect on performance and carcass characteristics of nursery to finisher pigs fed reduced crude protein, amino acid-supplemented diets. J. Anim. Sci., 73:433-440.

KYRIAZAKIS, I., DOTAS, D., EMMANS, G.C. 1994. The effects of breed on the relationship between feed composition and the efficiency of protein utilization in pigs. Br. J. Nutr., 71:849-859.

KYRIAZAKIS, I., EMMANS, G.C., WHITTEMORE, C.T. 1991. The ability of pigs to control their protein intake when fed in three different ways. Phys. and Behav., 50:1197-1203.

LE DIVIDICH, J.L., NOBLET, J. 1986. Effect of dietary energy level on the performance of individually housed early weaned piglets in relation to environmental temperature. Lvstck. Prod. Sci., 14:255-263.

LIMA, J.A.F., PEREIRA, J.A.A., COSTA, P.M.A. et al. 1990. Efeito da idade da desmama sobre as exigências de lisina para leitões na fase inicial de crescimento (15 a $30 \mathrm{~kg} \mathrm{PV}) . R$. Soc. Bras. Zootec., 19:390-399.

LONGMILLER, J.A., NELSSEN, J.L., GOODBANDA, M.D. et al. 1998. Influence of dietary lysine on growth performance and a carcass characteristics of late-finishing gilts. J. Anim. Sci., $76: 1075-1080$. 
484 Rev. bras. zootec.

MILLER, P.S., LEWIS, A.J., CHEN, H.Y. 1998. Plasma urea can be used to identify the protein requeriments of group-penned finishing (130 to $220 \mathrm{lb}$ ) barrows and gilts fed corn-soybean diets. Nebr. Swi. Rep., p.26-29.

MORETTO, V., DONZELE, J.L., OLIVEIRA, R.F.M. Níveis de lisina para suínos machos inteiros, da raça Landrace, de 15 a $30 \mathrm{~kg}$ de peso. In: REUNIÃO ANUAL DA SOCIEDADE BRASILEIRA DEZOOTECNIA, 35, 1998, Botucatu. Anais... Botucatu, 1998 p.496-498.

NUTRIENT requeriments of swine. 1988. 10.ed. Washington, DC: NCR.

OLIVEIRA, R.F.M., DONZELE, J.L., FREITAS, R.T.F. et al. 1997a. Efeito da temperatura ambiente sobre o desempenho e sobre parâmetros fisiológicos e hormonais de leitões consumindo dietas com diferentes níveis de energia digestível. R. Bras. Zootec., 26:1173-1182.

OLIVEIRA, R.F.M., DONZELE, J.L., FREITAS, R.T.F. et al. 1997b. Níveis de energia digestível para leitões dos 15 aos $30 \mathrm{~kg}$ de peso mantidos em ambiente de conforto térmico. R. Bras. Zootec., 26:539-547.

PERDOMO, C.C. Conforto ambiental e produtividade de suínos. In: SIMPÓSIO LATINO-AMERICANO DE NUTRIÇÃO DE SUÍNOS, 1994, São Paulo. Anais... São Paulo: CBNA, 1994. p.19-26.

RINALDO, D., LE DIVIDICH, J. 1991. Assessement of optimal temperature for performance and chemical body composition of growing pigs. Lvstck. Prod. Sci., 29:61-75.
ROSTAGNO, H.S., SILVA, D.J., COSTA, P.M.A. et al. 1992. Composição de alimentos e exigências nutricionais de aves e suínos: tabelas brasileiras. Viçosa, MG:UFV. 59p.

SCHENCK, B.C., STAHLY, T.S., CROMWELL, G.L. 1992. Interactive effects of thermal environmental dietary aminoacid and fat levels on rate and efficiency of growth of pigs housed in a conventional nursery. J. Anim. Sci., 70:3803-3811.

SILVA, D.J. 1990. Análise de alimentos: métodos químicos e biológicos. Viçosa-MG: UFV, Imprensa Universitária. 166p.

SOUZA, A.M. Exigências nutricionais de lisina para suínos mestiços, de 15 a 95 kg de peso. Viçosa, MG:UFV, 1997, 81p. Dissertação (Mestrado em Zootecnia) - Universidade Federal de Viçosa, 1997.

UNIVERSIDADE FEDERAL DE VIÇOSA-UFV. 1982. Manual de utilização do programa SAEG (Sistema para Análises Estatísticas e Genéticas). Viçosa-MG. 59p.

Recebido em: 12/02/99

Aceito em: 29/08/99 